\title{
MedCanHub: a platform developed by Cellen aimed at reducing barriers of access to unlicensed cannabis-based medicinal products during the COVID-19 pandemic
}

\author{
Authors: Lim Zhen Zong, ${ }^{\mathrm{A}}$ Mala Mawkin, ${ }^{\mathrm{A}}$ Haggai Sharon, ${ }^{\mathrm{B}}$ Michael Barnes, ${ }^{\mathrm{C}}$ Panagiotis Pardalidis, ${ }^{\mathrm{A}}$ Sarah Marten, ${ }^{\mathrm{D}}$ \\ Giancarlo Camilleri ${ }^{E}$ and Benjamin Viaris de Lesegno ${ }^{D}$
}

\begin{tabular}{|c|c|c|}
\hline Topic/segment & New prescribers & Experienced prescribers \\
\hline Setup: registration to CDAO, guidelines creation, interaction with $C Q C$, compliance audit. & 5 & 2 \\
\hline $\begin{array}{l}\text { Education: training on endocannabinoid system, CBMPs legal status in the UK, existing } \\
\text { products. }\end{array}$ & 5 & 2 \\
\hline $\begin{array}{l}\text { Product: labelling, absorption method, terpenes profile, content, price, delivery and } \\
\text { personalisation. }\end{array}$ & 4 & 4 \\
\hline Prescribing support: MDT, titration, dosage limit, patient eligibility, reminders. & 5 & 3 \\
\hline $\begin{array}{l}\text { Admin: researching patient information, writing and mailing prescriptions, shared care } \\
\text { management. }\end{array}$ & 3 & 4 \\
\hline Treatment tracking: patient scoring and scientifically validated questionnaires. & 3 & 5 \\
\hline
\end{tabular}

\section{Introduction}

Unlicensed cannabis-based medicinal products (UCBPMs) were reclassified from Schedule 1 to Schedule 2 in 2018 in the UK, allowing doctors on the Specialist Register of the General Medical Council to legally issue prescriptions for UCBPMs. ${ }^{1,2}$ However, there has been evidence showing that patients face difficulties in accessing UCBPMs, with the NHS only prescribing 18 out of a total of 259 UCBPMs prescriptions in the UK in $2019^{3}$ despite a 2019 YouGov poll reporting about 1.4 million patients self-medicating with cannabis. ${ }^{4}$ The ongoing COVID-19 pandemic has exacerbated this problem, with border crossing and import supply chains facing disruptions. Reports investigating the barriers to accessing UCBPMs on the NHS list the lack of knowledge and education of cannabis use and its benefits as one of the main problems. ${ }^{5}$ As such, despite $92.8 \%$ of specialists surveyed reported having asked by patients to prescribe medical cannabis, most did not have the confidence to prescribe it. ${ }^{6,7,8}$

Authors: ${ }^{\mathrm{A}}$ Imperial College London, London, UK; ${ }^{\mathrm{B}}$ Guy's and St Thomas' Pain Management and Neuromodulation Centre, London, UK; ' Medical Cannabis Clinician Society; ${ }^{D}$ Cellen Life Sciences;

${ }^{E}$ Ashford and St Peter's NHS Foundation Trust, Surrey, UK
Cellen Therapeutics, an independent, UK-based UCBPMs research organisation aiming to make UK UCBPMs prescriptions more transparent and accessible, decided to develop the MedCanHub platform, to increase the proficiency and confidence of doctors to prescribe.

\section{Methods}

Qualitative data were collected from interviews conducted with 14 prescribers. They shared problems encountered with current UCBPMs prescription and suggested areas of improvement.

The interviews focused on four main themes: pre-consultation, during consultation, post-consultation, and additional resources. A composite score was applied to grade the different themes according to their relative importance to prescribers, from $5=$ very important to $1=$ not important at all. The result guided the development of the MedCanHub.

\section{Results}

The results of the interviews are shown in Table 1.

Prior to consultation, the MedCanHub supports prescribers by describing the process to acquire a controlled drug private prescriber number and with a checklist of contraindications.

For consultation support, we developed a literature review of validated dosage of THC and CBD, a checklist of information to 
deliver to patients, a list of UCBPMs oils available in the UK, a treatment planner creation tool, and a sample prescription.

Post-consultation support includes tools to generate CQC compliant letters, sending a prescription and how to report drug incidents to the MHRA.

Lastly, links to online training, regulations and guidelines are included.

\section{Discussion}

The MedCanHub software was developed to support consultants during COVID-19 in the process of UCBPMs prescriptions, from pre-consultation to post-consultation. $100 \%$ of the surveyed specialists would recommend the platform to colleagues who are looking to support their patients with UCBPMs prescriptions. As a result, we believe that by providing consultants with sufficient information, they can better support patients during the pandemic.

\section{Conflicts of interest}

This paper was authored by medical undergraduate students and consultant specialists with information regarding software provided by the team at Cellen Life Sciences.

\section{References}

1 Home Office. Government announces that medicinal cannabis is legal. GOV.UK, 2018. www.gov.uk/government/news/governmentannounces-that-medicinal-cannabis-is-legal [Accessed 03 October 2020].

2 NHS England. Barriers to accessing cannabis-based products for medicinal use on NHS prescription: findings and recommendations. NHS, 2019.

3 Care Quality Commission. The safer management of controlled drugs: update report for 2019. London: CQC, 2019.

4 Medical Cannabis Network. Patient access to cannabis in the UK: Cellen breaks down barriers. Medical Cannabis Network, 2020. www.healtheuropa.eu/uk-patient-access-to-cannabis/100827 [Accessed 04 October 2020].

5 Mahase E. Medical cannabis: patients turn to private clinics because of NHS void. BMJ 2019;209;15290.

6 Conservative Drug Policy Reform Group. The UK review of medicinal cannabis: The needs of a nation. Conservative Drug Policy Reform Group, 2020.

7 Yen J, DeGroote MG, Bhayani S. A survey of knowledge of cannabis in pain physicians: BJP ASM Poster Abstracts 2020. British Journal of Pain 2020;14(1_suppl):5-36.

8 Medicines and Healthcare products Regulatory Agency. The supply, manufacture, importation and distribution of unlicensed cannabisbased products for medicinal use in humans 'specials'. MHRA, 2018. 